\title{
BUDAYA PESANTREN DALAM MEMBENTUK PERILAKU ISLAMI SANTRI DI PESANTREN AL-AZHAAR LUBUKLINGGAU
}

\author{
Ratna Wulan Sari \\ Mahasiswa S3 UIN Raden Fatah Palembang \\ Jurusan Peradaban Islam (PI) Konsentrasi Islam Nusantara \\ email :ratnawulansari2015@gmail.com \\ Wahyu Rizky Andhifani \\ Balai Arkeologi Sumatera Selatan
}

\begin{abstract}
The main subject of this research is to know the role of Islamic boarding schools in applying Islamic boarding school culture as the implementation of Islamic boarding school culture towards the formation of Islamic students in Al-Azhaar Islamic Boarding School. The Complianced with implementing regulations and habituation in Islamic boarding schools has not be fully done by santri, so that there are still violations in ethic. This study will discuss the topic of Islamic Boarding School in Establishing Islamic Student's Behavior in Al-Azhaar Lubuk Linggau Islamic Boarding School by phenomenological approached, where through this approach can be described pesantren cultural phenomena in shaping behavior Islamic Stucents who are visible in the field so that they can be interpreted the meaning and contents of Islamic values in santri properly.
\end{abstract}

Keywords: Culture of Islamic Church, Islamic Behavior, Islamic Students in Islamic Boarding Schools

Abstrak: Pokok kajian penelitian ini untuk mengetahui peran pesantren dalam menerapkan kultur pesantren sebagai penanaman nilai-nilai Islami pada santri, bagaimana implementasi budaya pesantren terhadap pembentukan perilaku Islami santri di lingkungan Pesantren Al-Azhaar. Kepatuhan untuk melaksanakan peraturan-peraturan dan pembiasaan-pembiasaan yang dilakukan dalam lngkungan pesantren belum dapat di lakukan santri sepenuhnya, sehingga masih saja terdapat pelanggaran-pelanggaran dalam etika. Penelitian ini akan membahas Topik Budaya Pesantren dalam Membentuk Perilaku Islami Santri di Pesantren Al-Azhaar Lubuklinggau dengan menggunakan metode kualitatif dan dengan menggunakan pendekatan fenomenologi, dimana melalui pendekatan ini dapat digambarkan fenomena kultur pesantren dalam membentuk perilaku Islami santri yang nampak di lapangan sehingga dapat diinterpretasikan makna dan isinya secara mendalam.

Kata Kunci : Budaya Pesantren, Prilaku Islam, Santri di Pesantren

\section{Pendahuluan}

Pesantren merupakan produk budaya Indonesia Asli, yang berkembang sejalan dengan proses islamisasi dinusantara. Melihat dari latar belakangnya, pesantren tumbuh dan berkem- bang dengan sendirinya dalam masyarakat yang terdapat implikasi-implikasi politis kultural yang menggambarkan sikap ulama Islam sepanjang sejarah (Djamaluddin, 1999). Seiring dengan perkembangan zaman, pesantren telah banyak 
menggalami penyesuaian-penyesuaian menurut proses perubahan sosial dalam masyarakat dengan tanpa meninggalkan keaslian dan kekhasan yang dimilki pesantren sebagai khasanah tradisi budaya bangsa yang menjadi sebah keniscahayan di tengah dasyatnya perkembangan teknologi yang moderen (Yasmadi,2002:152). Umunnya pesantren didirikan perorangan (Kyai) sekaligus juga berfungsi sebagai figur central dan mempunyai daulat kuat dalam menetapkan tujuan yang di cita-citakan pesantrennya. Namun demikin dalam menetapkan rumusan formal tujuan akhir pesantren harus tetap bersifat comprensif dan intergal dengan landasan idil negar yaitu pancasila.

Sebagai sebuah budaya yang kaya akan nilai-nilai, keyakinan dan budaya, dimana hal itu biasannya selalu nampak dalam lingkungan kehidupan keseharian pesantren. Budaya pesantren tersebut dengan sengaja dibentuk atau diciptakan oleh pemimpin dan pengasuh pesantren tersebut dengan sengaja di ciptakan oleh pemimpin dan pengasuh pesantren dalam proses pembinaan dan pendidikan pesantren untuk mencapai tujuan yang diinginkan oleh pesantren tersebut. Sehingga fungsi budaya pesantren sebagai pola prilaku yang menentukan batas batas perilaku yang telah disepakati oleh seluruh warga pesantren dan sebagai tata nilai yang merupakan gambaran prilaku yang diharapkan dari warga pesantren dalam mewujudkan tujuan pesantren dapat terlaksana dengan sebaik-baknya. Dimana ada nilai yang dimaksut adalah alkulturasi dari keyakinan seseorang sebagai pengabdian kepada tuhan yang maha esa. (Ndraha, 2003:45).

\section{Metode Penelitian}

Penelitian lapangani ini menggunakanmetodekualitatif yang berlokasi di Pesantren AlAzhaar Lubuklinggau. Jenis data yang digunakan adalah berbentuk deskriptif baik berupa katakata hasil pembicaraan), hasil pengamatan terh- adap perilaku santri. Sumber data primer adalah pimpinan, ustad/ustadzah dan santri. Sedangkan sumber data skunder berupa buku-buku dan dokumentasi pesantren yang berkenaan dengan penelitian ini.

Dalam pengumpulan data kualitatif menggunakan observasi, wawancara, dan dokumentasi. Setelah data terkumpul kemudian di periksa keabsahannya, dan selanjutnya data tersebut dengan diklasifikasiakn sesuai dengan aspekaspek masalah yang ada, lalu disederhanakan, disajikan dan ditarik kesimpulan dan di peroleh hasil analisis penelitian dilakukan dengan cara deskriptif kualitatif.

\section{Pembahasan}

Penerapan Kultur Pesantren Dalam Membentuk Perilaku Islami Santri di Pesantren Pesantren Alzahaar Lubuklinggau.

Berdasarkan hasil wawancara dengan pimpinan Pesantren Al-Azhaar Ahmad Mansur, kultur pesantren di terapkan pada santri dengan berpedoman pada aturan dan peraturan yang dibua toleh pimpinan. Semua warga pesantren termasuk pula pimpinan, pengasuh, ustad, ustazah, penjaga dan seluruh santri harus ikutserta dalam rangka menjalankan aturan ataupun peraturan tersebut.

\section{Bidang Pendidikan dan Pengajaran}

Metode dan sistem pengajaran serta kurikulum yang dijalankan di Pesantren Al-Azhaar. Sunnah merupakan kombinasi antara tradisionald an modern. Untuk pendidikan dan pengajaran non formal atau sering disebut pendidikan diniyah biasanya dalam bentuk pengajian yang dilakukan setelah sholat ashar hingga menjelang maghrib dan kemudian dilanjutkan kembali hingga menjelang isya. Pesantren Al-Azhaar juga sangat menekankan dibidang Al-Quran. Dimana para santri diwajibkan untuk mengikuti pengajian yang diselenggarakan dengan dua macam 
carayaitusantri yang mengaji dengan cara membaca mushaf Al-Quran dan santri yang mengaji dan menghafal Al-Quran.

\section{Aturan Peraturan}

Pimpinan pesantren telah membuat aturan dan peraturan bagi seluruhwargapesantrenbaiktertulismaupuntidaktertulis.Peraturantersebutbersifaatmengikatdanwajibdijalankanoleh guru (ustadzataupunustadzah), santridanmasyarakat di dalampesantrentermasukkaryawanbaikadministrasi, petugasdapur, petugaskebersihan, danpetugaskeamanan.

\section{a. Bagi Guru (Ustadz ataupun Ustadzah )}

Pimpinan telah membuat peraturan yang telah dibuat di Pesantren Al-Azhaar telah mengatur perihal guru dan pengasuh. Tentang etika guru, bahwas etiap guru (Ustadz ataupun Ustadazah) wajib menjaga dan menjunjung tinggi integritas (akhlakulkarimah, kejujuran dan kemandirian). Guru (Ustadz ataupun Ustadzah) diwajibkan pula untuk membuka komunikasi seluas-luasnya dengan orang tua siswa dan masyarakat dan juga wajib menjunjung tinggi budaya hormat kepada orang yang dituakan. Presentasi kehadiran guru juga menjadi perhatian pimpinan pesantrenbahwa guru (ustadz ataupun ustadzah) wajib memberiakan motivasi belajar kepada siswa serta guru ( ustadzat ataupun ustadzah ) yang mengajar pada jam terahir wajib membimbing siswa sholat berjama'ah. Dalam hal berpakaian guru harus rapi, bersih dan sopan.

\section{b. Bagi Santri}

Untuk dapat mencapai keberhasilan dalam pembinaan santri secara baik, maka pesantren telah membuat dan membagikan bukusantri yang berisi jadwal kegiatan hariansantri. Dimana dalam bukuter sebut tercantum beberapa kegiatan yang harus dijalani santri, mulai dari 03.30 pada pagi hari sampai dengan 21.15 WIB malamhari.
Dengan adanya jadwal-jadwal yang tersusun sedemikian rupa maka pimpinan Pesantren AlAzhaar sangat berharap agar santri dapat mematuhinya dan akan menjadi pedoman santri untuk melakukan segala aktivitas pendidikan dan pengajaran di PesantrenAl-Azhaar. Jenis kegiatan santri yang begitu banyak namun terjadwal dengan baik, diatur dari mulai bangun tidur, jadwal sholat, jadwal makan, sekolah, mengaji, berpuasa sunah, menghapal Al-quran dan kegiatan hari-hari besar Islam, termasuk juga berpuasa pada sunah pada hari senin kamis sampai tidur malam kembali juga sudah terjadwal. Dari awal santri masuk kedalam lingkungan pesantren (asrama) sosialisasi sudah wajib di berlakukan.

\section{c. Bagi karyawan}

Untuk dapat berjalannya dengan suksessemua kegiatan di pesantren, tentunya peran semua warga pesantren sangat diharapkan, termasuk juga karyawan, petugas yang ada di dalam pesantren Alzahaar. Pimpinan pesantren juga mengingatkan karyawan agar memberikan motivasi kepada santri dan warga Pondok agar tidak boros dan tidak jajan pada waktu santri sedangberpuasasunah.

\section{Peran Pesantren Dalam Memberikan Tela- dan}

Peraturan dan tata tertib yang telah dibuat oleh pesantren yang semuanya harus dijalankan dan dipatuhi, dan sebagai acuan dalam melaksanakan kegiatan sehari-hari. Bagi para pengajar juga ada pedoman yang telah dibuat dan di sepakati yang harus dipatuhi agar dalam berintegrasi dengan santri dapat dilakukan dengan cara-cara yang baik dan terarah untuk lebih baik. Baik guru (ustadz ataupun ustazah) sangat dituntun untuk berahlak mulia baik perkataan maupun perbuatan. Memberi contoh teladan tepat pada waktunya dalam setiap kegiatan baik formal dalam proses belajar mengajar dikelas maupun dalam 
82

NUANSA Vol. XII, No. 1, Juni 2019

kegiatan di luar kelas. Memberi contoh yang baik dalam bertutur kata yang sopan dan berbuatbaik serta saling membantu dan toleransi yang sangat dijaga diantara santri. Berikut keterlibatan santri dalam budaya pesantren (internal), maupundari lingkungan diluar pesantren (eksternal) :

\section{Implikasi Budaya Pesantren Terhadap Prilaku Islami Santri}

Peran pesantren dalam hal ini (Kyai ataupun wakil Kyai) sebagai pembuat aturan ataupun peraturan dalam pesantren telah mampu membangun budaya dengan baik. Implikasi budaya pesantren terhadap pembentukan prilaku Islami santri di pesantren Alzahaar Lubulinggau, berdasarkan hasil wawancara serta diperkuat dengan hasil observasi telah menunjukkan kearah yang di cita-citakan. Artinya penerapanbudaya pesantren telah dapat menimbulkan kesadaran diri pada santri atas apa yang berlaku di pesantren. Aturan dan berbagai kegiatan yang mendukungnya memunculkan implikasi internal dan eksternal. Dimana implikasi internal dapat dilihat dari :

\section{a. Terjalin Komunikasi Dan Hubungan Akrab Antara Kyai (Ustad/Ustazah) dengan Santri}

Hubungan sosial yang terjadi antar santri, ustad dan ustazah terjalin dengan baik, dimana hubungan tersebut merupkan interaksi sosial yang bersifat dinamis baik menyangkut hubungan antara individu dengan individu, antara kelompok-kelompok orang, antara individu dengan kelompok manusia :

1. Hubungan antar Kyai dan santri telah mengalami banyak perkembangan. Dimana Kyai secara tradisional dianggap mempunyai tingkat keimanan yang tinggi dan di segani oleh masyarakat sebagai tokoh yang menjadi panutan yang mempunyai kharismatik.

2. Hubungan santri dengan santri, tumbuh dalam sistem sosial tersendiri di pesantren.
Dimana hubungan yang terjadi antar santri adalah hubungan-hubungan yang bersifat pertemanan dan kekeluargaan (Galba, 1995:5-61).

\section{b. Kemandirian dan KedisiplinanSantri}

Kemandirian dan kedisiplinan santri ditunjukkan dari cara berprilaku, mulai dari bangun tidur sampai beranjak tidur lagi, para santri membiasakan diri untuk displin terhadap norma dan nilai yang berlaku di pesantren. Pembentukan perilaku Islami santri melalui kedisiplinan juga sangat dituntut di pesantren. Dimana santri yang melakukan pelanggaran di pesantren Alzahaar terhadap aturan maka akan di kenakan sanksi/hukuman. Hukuman ada yang berupa teguran yang sifatnya ringan maupun berat dan di kelurkan dari Pesantren Al-Azhaar.

Pembentukan perilaku Islami melalui kedisiplinan juga sangat dituntut di pesantren Alzahaar. Dimana santri yang melakukan pelanggaran, biasanya dicatat dan di masukan kedalam buku hitam sehingga santri bisa menyadari akan kesalahnnya dan berjanji tidak akan mengulangi kesahannya lagi dan berjanji akan menepati dan mematuhi aturan-aturan yang telah dibuat olehpesantren.

Implikasi eksternal dapat dilihat dari faktor eksternal santri dengan kehidupan di lingkungan luar Pesantren Al-Azhaar

1. Berbakti kepada kedua Orang Tua dan berbuat baik kepada sesama

Berbakti kepada orang tua adalah hal yang memang harus dilakukan dan adalah kewajiban kita sebagai anak, sehingga santri bisa melaksanakan perintah orang tua dan berusaha membahagiakan orang tua. Terutama ditunjukan dengan jalan bersikap sopan santun, berbicara lembut, membantu semua pekerjaan orang tua di rumah dan meringankan beban orang tua bagi yang sudah bisa bekerja dan cukup umur. 
Sebagai makhluk sosial, manusia tidak bisa lepas dari orang lain, karena manusia adalah mahluk sosial yang juga membutuhkan orang lain, karna tanpa orang lain kita tidak akan bisa sendiri, sehingga dalam berintegrasi dengan orang lain,kita sebagai manusia untuk saling menghargai dan saling membantu kepada sesama.

\section{Menanamkan nila-inilai religius santri di luar lingkungan pesantren}

Berkembangnya nilai-nilai religius santri dimulai dari diri santri itu sendiri, melalui sikap jujur, darmawan, bijaksana, sopan santun, berbicara dengan tutur kata lembut dan terarah dan mempunyai tanggug jawab. Santri juga di dalam pergaulan harus bisa melaukakan dan menunjukan hal-hal yang positif dan tidak berbuat yang mengarah kearah fitnah serta dapat menahan amarah dan menahan hal-hal yang di larang dalam ajaran agama Islam.

\section{Hambatan dan kendala}

Ada juga Beberapa hambatan yang di temui ustazad dan ustazah dalam menerap kan budaya di Pesantren Al-Azhaar, terutama untuk santri yang baru masuk dalam lingkungan pesantren, karena mereka masih membawa budaya mereka sendiri dari asal meraka, yang mana harus disesuaikan dengan budaya Pesantren Al-Azhaar sehingga membutuhkan waktu dan proses untuk menyesuaikannya dan kadang juga butuh kesabaran. Selain dari budaya dan latar belakang meraka yang berbeda juga dalam hal kemampuan dasar mereka yang berbeda, tetapi dengan diterapkan peraturan dan budaya belajar dengan terjadwal maka para santri bisa mengasah kemampuannya sehingga dengan lambat laun pun kemampuan santri meningkat.

\section{Kesimpulan}

Pesantren Al-Azahaar mempunyai Budaya dalam memanjukan santri-santri, dan mempunyai tingkat kesulitan yang berbeda-beda dalam membentuk kedisiplinan yang telah di buat dalam aturan aturan khusus. Pesantren Al-Azhaar dalam menerapkan aturan - aturan tersebut dan harus dilaksanakan dari mulai santri-santri tersebut masuk dalam lingkungan Pesantren Al-Azhaar. Salah satu contoh aturan yang dibuat dari Pesantren Al-Azhaar adalah membuat aturan dari awal bangun tidur, sholat sunat maupun shoat fardu, membaca Alquran, menghapalAlquran dan kegiatan-kegiatan lainnya sudah terprogram dan mempunyai sangsi apabila terjadi pelanggaran. Hambatan yang ditemui ustazah dan ustad dalam menerapkan budaya kadang Mempunyai Hambatan, terutama untuk santri yang baru masuk dalam lingkungan pesantren, karena mereka masih membawa budaya mereka sendiri dari asal meraka, yang mana harus disesuaikan dengan budaya Pesantren Al-Azhaar sehingga membutuhkan waktu dan proses untuk menyesuaikannya. Sangsi yang diberikan berbeda-beda dari yang ringan sepertiteguransampai yang berat dan dikeluarkan dari pesantren. Hasil penelitian menunjukkan: pertama, Pesantren Al-Azhaar mempunyai peran kuat dalam pelaksanaan budaya pesantren dimana pimpinan pesantren telah membuat suatu aturan dan peraturan dalam bentuk SOP (Standar Operational Prosedure), jadwal-jadwal harian, mingguan dan bulan. Kedua, implementasi budaya pesantren dalam lingkungan Pesantren Al-Azhaar Lubuklinggau dilakukan transformasi nilai-nilai agama islam dengan proses penanaman kebiasaan. Ketiga implikasi kultur di Pesantren Al-Azhaar telah menunjukkan perubahan yang semakin baik, baik dalam sikap, tata krama, perilaku santri, kemandirian serta kedisiplinan. 
84 NUANSA Vol. XII, No. 1, Juni 2019

\section{Daftar Pustaka}

Arikunto, Suharsimi, 20110. Prosedur Penelitian Suatu Pendekatan Praktik, Jakarta : Rineka

Daradjat, Zakiah, 1990. MembinaNilai-Nilai Moral di Indonesia, Jakarta :BulanBintang

Galba, Sindu, 1995. PesantrenSebagaiWadahko munikasi,Jakarta : PT. RinekaCipta

Hajjaj, Muhammad Fauqi, 2013. Tasawuf Islam danAkhlak Yang Luhur, Jakarta : AMZAH

Hidayah, Ara, danMachali, Imam. 2012. PengelolaanPendidikan. Yogyakarta :Kaukaba

Labovitz, Sanfor dan Hegedorn, Robert, 1982. Metode Riset Sosial Suatu Pengantar, terjemahan, Jakarta : Erlangga
Ndraha, Takliziduhu, 2003. BudayaOrganisasi, Jakarta : PT. RinekaCipta

Patton, Michael Quinn, 1990. Qualitative Evaluation and Research Methods, Newbury Park: Sage

Taylor SJ danBogdan R, 1984, Introduction To Qualitative Research Methods : The Search for Meaning, secondEdition, JhonWiley and Sons, Toronto

Wawancara, Ahmad Mansur, 8 Agustus 2018

Wawancara, Qoriah, 8 November 2018

Wawancara, Ahmed, 10 Januari 2019

Yasmadi, 2002. Modernisasi Pesantren kritik Nurcholish Madjid Terhadap Pendidikan Islam Tradisional, Jakarta :Ciputat Press 